\title{
Dynamic Response Analysis of Liaocheng Guangyue Tower Under the Ground Traffic Load
}
Zhaobo Meng, a, Bosen $\mathrm{Hu}^{2, \mathrm{~b},}$ Qingshuang Zhao ${ }^{1, \mathrm{c}}$, Jie Jin ${ }^{1, \mathrm{~d}, \text { and Dukuo }}$ Song ${ }^{1, e}$

${ }^{1}$ School of Architecture\& Civil Engineering, Liaocheng University, Liaocheng, 252059,China

${ }^{2}$ School of Engineering Xi'an University of Architecture and Technology, Xi'an, 250022,China

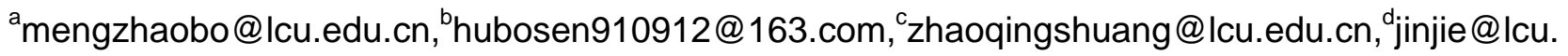

$$
\text { edu.cn , }{ }^{e} \text { lixifeng@lcu.edu.cn }
$$

Keywords: Liaocheng Guangyue Tower; Ground Traffic Load; Dynamic Response; security assessment

Abstract. This paper takes liaocheng Guangyue Tower for study, it uses the 1/4 vehicle model of zhongtong bus LCK6105HGC,and it makes dynamic response analyses when ancient timber structure's speed is $20 \mathrm{~km} / \mathrm{h}$ and $40 \mathrm{~km} / \mathrm{h}$. The results show that when the vehicle speed is $40 \mathrm{~km} / \mathrm{h}$, horizontal vibration velocity of the top column is 1.03 times than when vehicle speed is $20 \mathrm{~km} / \mathrm{h}$. According to Technical specifications for protection of historic buildings against man-made vibration, horizontal vibration velocity of the top column is $0.156 \mathrm{~mm} / \mathrm{s}$, and it is less than the limited one which is $0.196 \mathrm{~mm} / \mathrm{s}$.

\section{Introduction}

Guangyue tower is located in center of Liaocheng city. It's founded in 1374, which is composed of two parts of the high pedestal and the upper timber structure. The high pedestal is four prism. The length of the bottom edge is $34.43 \mathrm{~m}$ and on the bottom side is $31.62 \mathrm{~m}$ respectively. The height of this historic timber structure is $9.38 \mathrm{~m}$. On the wall of the four directions, there is one semicylinder arch in each wall, the center of the cross is the intersection of the arch form. The width of each arch is $5.76 \mathrm{~m}$ and the vertical height is $2.88 \mathrm{~m}$. The upper timber structure is located in the central of high stylobate, which have four layers and 24 meters high. It is shown in Fig.1.

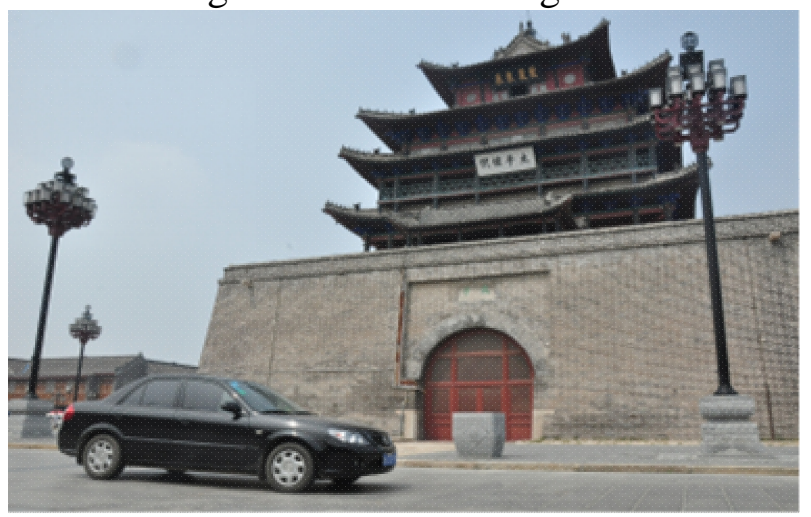

Fig.1 The panorama of Guangyue tower

\section{Material parameters and section sizes}

The material parameters and beam-column section sizes of the timber structure are shown in Table 1 and Table 2. 
Table.1 material parameters.

\begin{tabular}{cccc}
\hline Materia & Elastic Modulus(MPa) & Density $\left(\mathrm{kg} / \mathrm{m}^{3}\right)$ & Poisson's Ratio \\
Wood & 8307 & 410 & 0.25 \\
Stylobate & 129 & 1780 & 0.175 \\
Soil & 20 & 1800 & 0.35 \\
\hline
\end{tabular}

Table.2 section of beam

\begin{tabular}{|c|c|c|c|c|c|}
\hline Name & $\begin{array}{l}\text { first and second } \\
\text { column }\end{array}$ & $\begin{array}{l}\text { third and fourth } \\
\text { column }\end{array}$ & first beams & second beams & $\begin{array}{l}\text { third and fourth } \\
\text { column }\end{array}$ \\
\hline Diameter(m) & 0.6 & 0.4 & $0.3 * 0.3$ & $0.21 * 0.37$ & $0.35 * 0.45$ \\
\hline
\end{tabular}

\section{Finite element model}

The upper beam and column are simulated by beam188 element. The high pedestal and soil used SOLID45 element simulation. The beam-column mortise and tenon connection node are simulated by spring element COMBIN14. The stiffness of mortise and tenon are $K_{x}=K_{z}=1.71 \times 10^{7} \mathrm{~N} / \mathrm{m}$, $\mathrm{K}_{\mathrm{y}}=2.08 \times 10^{8} \mathrm{~N} / \mathrm{m}$. The rotational stiffness are $6.244 \times 10^{8} \mathrm{~N} / \mathrm{m}[1]$. The finite element model of Guangyue tower is shown in Fig.2.

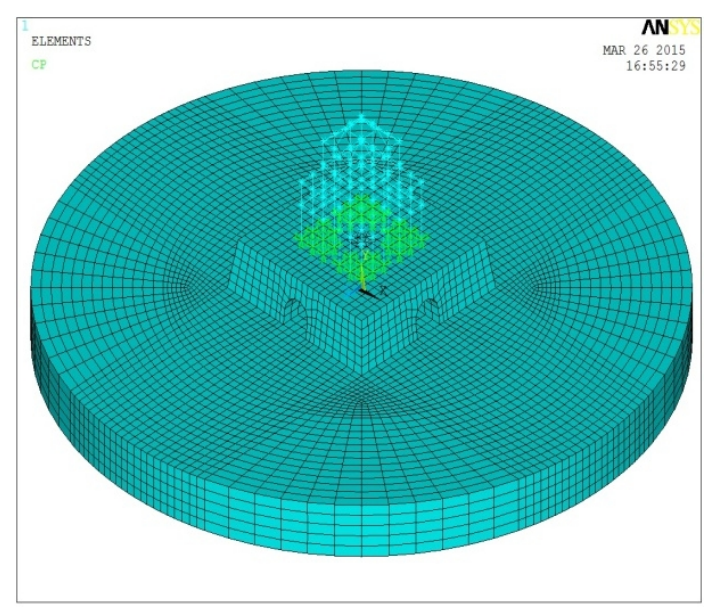

Fig. 2 The whole finite element model

\section{The dynamic response of Guangyue tower}

At present, there are mainly three kinds of vehicle models: 1/4 vehicle model[2], 1/2 vehicle model model[3] and the whole vehicle model, which is widely used as the vehicle model and the quarter vehicle model. A lot of experimental analysis shows that the $1 / 4$ vehicle model can accurately predict the vertical vibration of the vehicle. Therefore, this paper uses $1 / 4$ vehicle model. The vehicle load expression[4] is as follows:

$$
F(T)=P_{0}+P \sin (\omega t)
$$

In the formula: $P$ — static load of the wheel; $P$ - the amplitude of the vibration load, $P=M_{0} \alpha \omega^{2}, M_{0}$ represents a spring mass, $\alpha$ is the geometric irregularity rise, which reflect the condition of the road; $\omega$ is the vibration circle frequency, $v$ is the vehicle running speed, $L$ is the geometric curve (car length) pavement wavelength.

This paper select the representative of Zhongtong bus in the Liaocheng city with the LCK6105HGC simulation of ground traffic load, the whole vehicle quality $16000 \mathrm{~kg}$, rated capacity of 78 people.Taking the per person as $60 \mathrm{~kg}$, the total quality of the bus is $20680 \mathrm{~kg}$. For the specific 
parameters of the vehicle: single side static wheel weight $P_{0}=51.7 \mathrm{KN}$, spring quality $M_{0}=120 \mathrm{~N} \cdot \mathrm{S}^{2} / \mathrm{m}, \alpha=2 \mathrm{~mm}, L=10.5 \mathrm{~m}$.

This paper select the speed of $20 \mathrm{~km} / \mathrm{h}$ and $40 \mathrm{~km} / \mathrm{h}$ as excitation and take each of them into the equation (1) respectively:

$$
\begin{aligned}
& F(t)=51700+2.61 \sin (3.3 t) \\
& F(t)=51700+10.5 \sin (6.6 t)
\end{aligned}
$$

Using the equation (2) and (3), the load-time history and frequency spectrum can be obtained under different speed though Matlab software programming. It is shown in Fig.3 Fig.4.
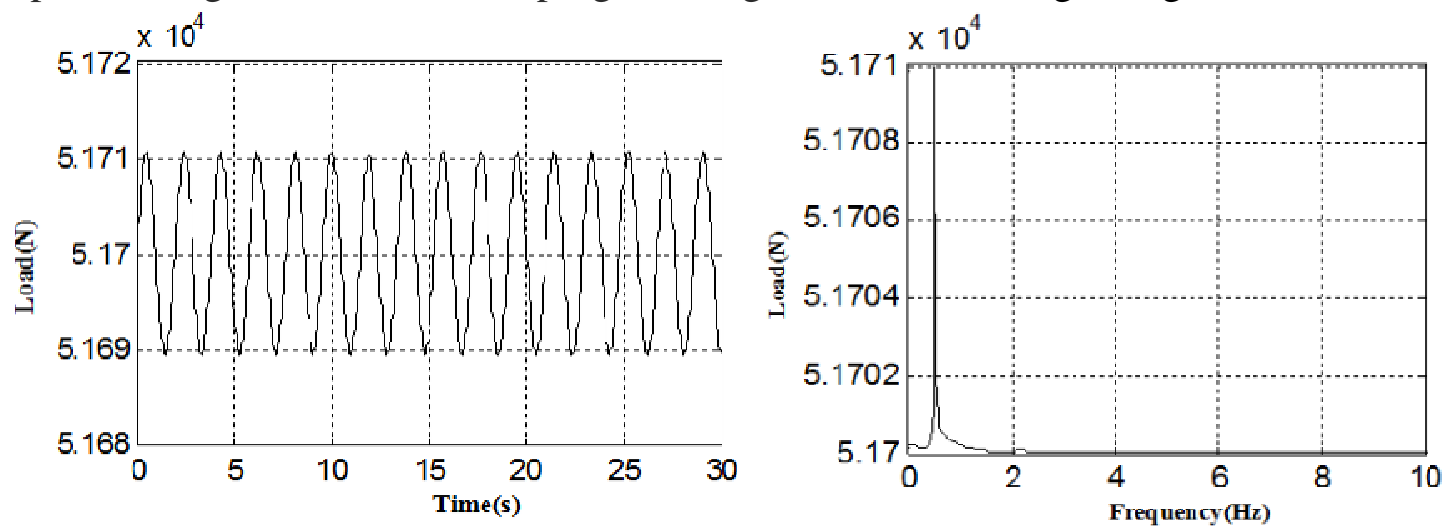

Fig.3 Load-time history and frequency spectrum $(\mathrm{v}=20 \mathrm{~km} / \mathrm{h})$
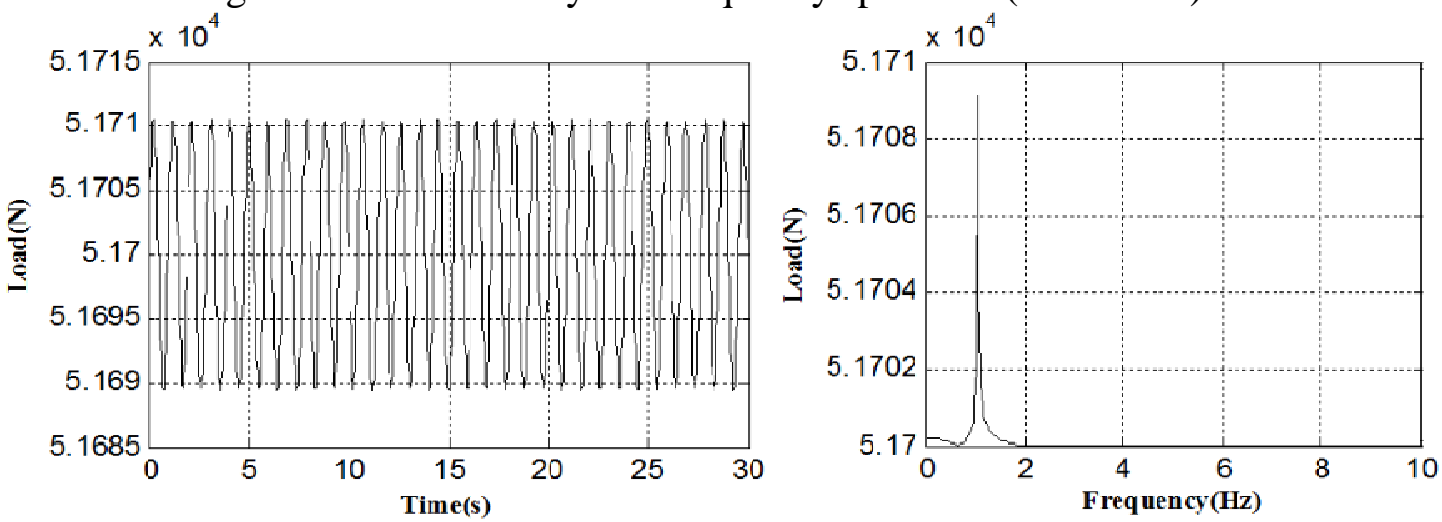

Fig. 4 Load-time history and frequency spectrum $(\mathrm{v}=40 \mathrm{~km} / \mathrm{h})$

To predict the traffic conditions in the rotary road of Guangyue Tower, this paper assume that the safety distance between two travelling vehicles is 40 meters. Meanwhile, according to length of the bus is $10.5 \mathrm{~m}$, it can calculated that the rotary road can accommodate up five buses at the same time. Taking the load to the finite element model and the load mode is shown in Fig.5.

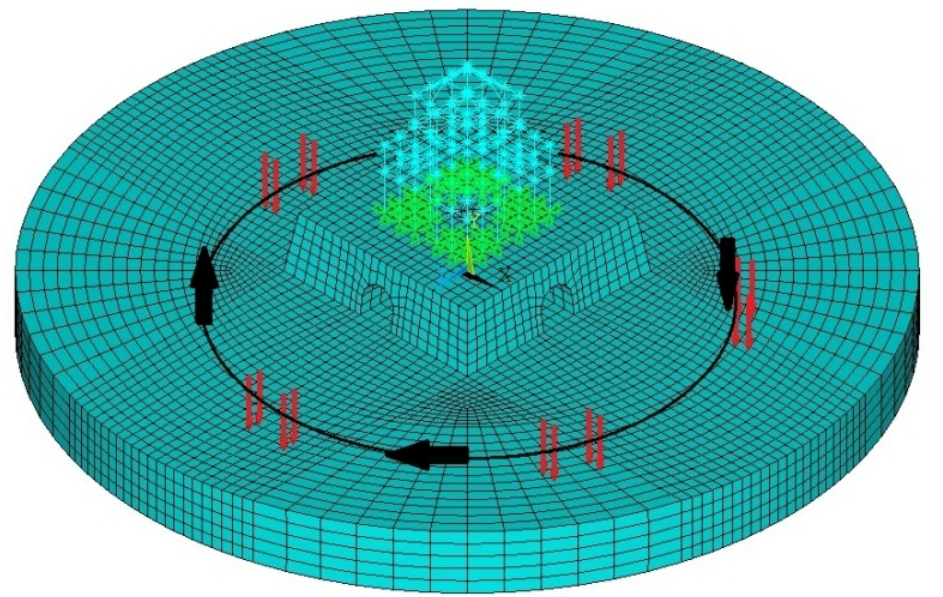

Fig.5 vehicle load mode 


\section{Analysis of calculation results}

To analyze the vibration of corner post and stele in Guangyue Tower every layer, this paper select eight vibration points. It is shown in Fig.6, the dynamic model divided eight vibration points into four groups. Each of them include two points which represent the top node of corner column and stele in Guangyue Tower each layer. Horizontal velocity amplitudes of every vibration points can be shown in Fig.7.

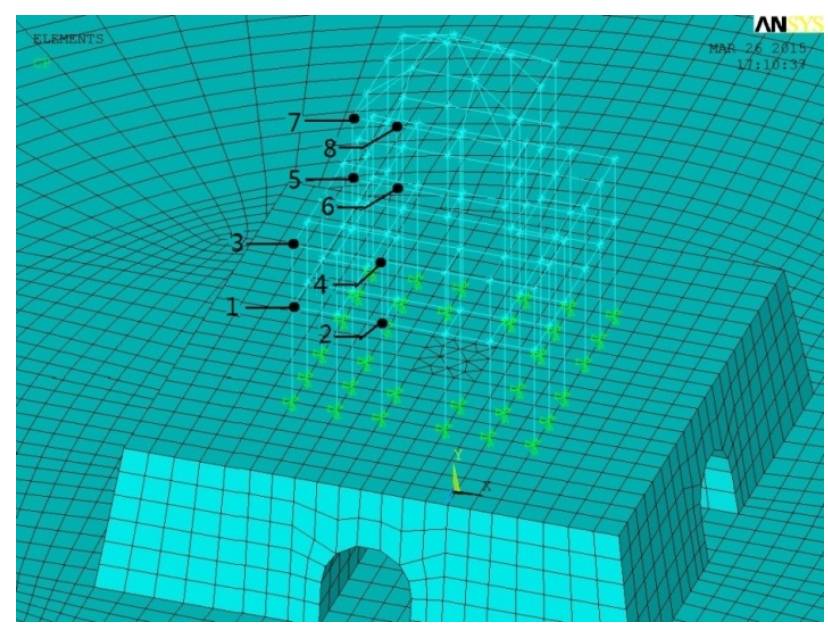

Fig.6 Schematic diagram of eight vibration points

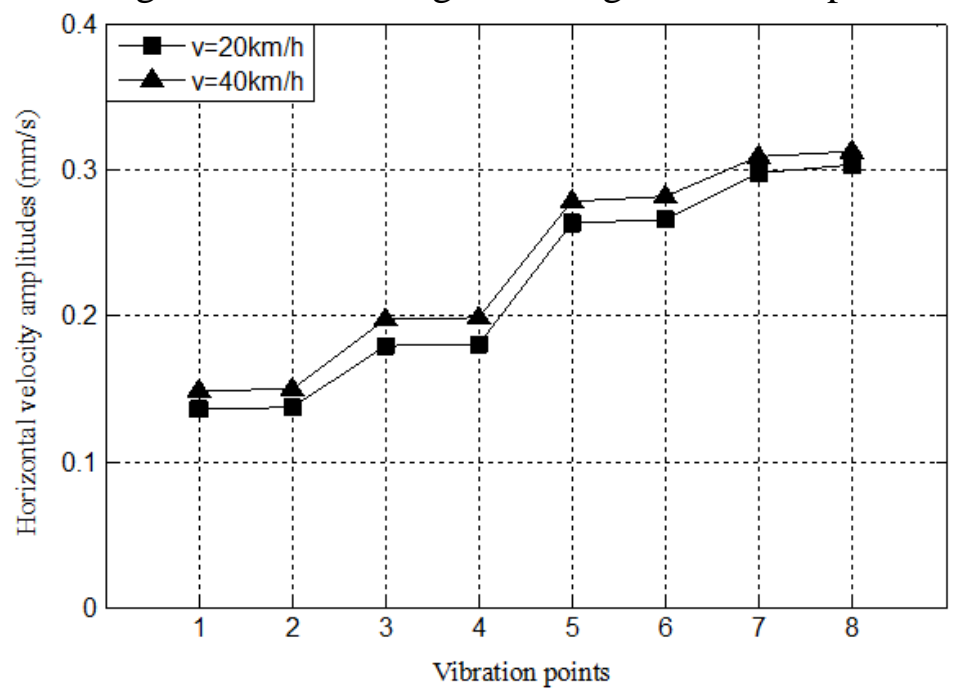

Fig.7 Horizontal velocity amplitudes of every vibration points

It is shown in Fig.7, the horizontal vibration velocity of stele in every layer is bigger than corner column slightly. Therefore, horizontal vibration velocity of the top of the column should be used to make traffic safety assessment; When the speed of travelling vehicles running at $40 \mathrm{~km} / \mathrm{h}$, the maximum horizontal vibration velocity of stele in each layers were $0.1497 \mathrm{~mm} / \mathrm{s}, 0.1993 \mathrm{~mm} / \mathrm{s}$, $0.2817 \mathrm{~mm} / \mathrm{s}, 0.3125 \mathrm{~mm} / \mathrm{s}$, which is more than the one when driving at a speed of $20 \mathrm{~km} / \mathrm{h}$ whose maximum horizontal vibration velocity were $0.1378 \mathrm{~mm} / \mathrm{s}, 0.1806 \mathrm{~mm} / \mathrm{s}, 0.2664 \mathrm{~mm} / \mathrm{s}, 0.3042$ $\mathrm{mm} / \mathrm{s}$.

\section{Safety Assessment}

According to Technical specifications for protection of historic buildings against man-made vibration [5], the historic timber structures vibration velocity limits is shown in Table. 3. 
Table 3 The permitted oscillatory velocity of historic timber structure

\begin{tabular}{cccccc}
\hline Protection rank & $\begin{array}{c}\text { Position of } \\
\text { controlled point }\end{array}$ & Direction of & controlled point & \multicolumn{2}{c}{ The permitted vibration velocity [mm/s] } \\
The key places of historic sites & Column top & Horizontal & 0.18 & $0.18 \sim 0.22$ & 0.2 \\
$\begin{array}{c}\text { under State Protection } \\
\begin{array}{c}\text { The key places of historic sites } \\
\text { under Province Protection }\end{array}\end{array}$ & Column top & Horizontal & 0.25 & $0.25 \sim 0.30$ & 0.3 \\
$\begin{array}{c}\text { The key places of historic sites under } \\
\text { City or county Protection }\end{array}$ & Column top & Horizontal & 0.29 & $0.29 \sim 0.35$ & 0.35 \\
\hline
\end{tabular}

Note: Using the insertion method when the $V_{p}$ is between the $4600-5600 \mathrm{~m} / \mathrm{s}$.

Guangyue tower belongs to the national key cultural relics protection units. The wood elastic wave velocity is among $4600 \mathrm{~m} / \mathrm{s}$ and $5600 \mathrm{~m} / \mathrm{s}$ and the mean is $5011 \mathrm{~m} / \mathrm{s}$. According to the standard, horizontal vibration velocity limit is $0.196 \mathrm{~mm} / \mathrm{s}$. Then, make safety assessment of Guangyue tower basis on the standard.

Horizontal vibration velocity amplitude of column cap in the five top colums is shown in Table 4 . Table.4 Horizontal vibration velocity of the top columns

\begin{tabular}{rccccccc}
\hline Number & Column 1 & Column 2 & Column 3 & Column 4 & Column 5 & Average \\
Peak & 0.312 & 0.313 & 0.312 & 0.312 & 0.313 & 0.313 & 0.156 \\
\hline
\end{tabular}

It can be seen from table 3, half of the horizontal speed of top of column cap the average peak value is $0.156 \mathrm{~mm} / \mathrm{s}$, which is less than the standard provisions of $0.196 \mathrm{~mm} / \mathrm{s}$.It is conclude that the Guangyue tower is in a safe state under traffic excitation.

\section{Conclusions}

This paper using 1/4 vehicle mode to make vibration response analysis of Guangyue tower when vehicle speed were taken $20 \mathrm{~km} / \mathrm{h}$ and $40 \mathrm{~km} / \mathrm{h}$. The results show that horizontal vibration velocity amplitude of column cap when vehicle speed in $40 \mathrm{~km} / \mathrm{h}$ is 1.03 times of $20 \mathrm{~km} / \mathrm{h}$. The measured horizontal vibration velocity is $0.156 \mathrm{~mm} / \mathrm{s}$ which less than the standard $0.196 \mathrm{~mm} / \mathrm{s}$ limit value. Therefore, It is conclude that the Guangyue tower is in a safe state under traffic excitation.

\section{Acknowledgements}

This work was financially supported by the National Natural Science Foundation of China (51378245). The State Cultural Relics Bureau Program（2013-YB-SQ-089） and Shandong Province Higher Educational Science and Technology Program (J14LG53).

\section{References}

[1] Weibing $\mathrm{Hu}$, Guangsen Han, Haiping Yu. The Analysis About Node Stiffness of Mortise and Tenon in Ancient Building[J]. Sichuan Building Science, 2011(6):44-47. In Chinese

[2] Zhuo Chen. Study On Dynamic Response Of Asphalt Pavement System For Heavy Duty Vehicles[D]. Lanzhou Industry University, Lanzhou,2005. In Chinese

[3] Zhong Hong Dong. Study on the Dynamic Response of Heavy Trucks and Asphalt Pavement. Chang'an University,Xi'an,2008. In Chinese

[4] GuangDong Qiao. Analysis of Dynamic Characteristics and Dynamic Response of Liaocheng Guangyue Tower under Traffic Excitation[D]. Xi'an University of Architecture and Technology,Xi ' an, 2014. In Chinese

[5] The standard of the People's Republic of China. Technical specifications for protection of historic buildings against man-made vibration. (GB/T50452-2008) [S] Beijin:China Building Industry Press,2008. In Chinese 